\title{
Sõnad palatis Keel, tervis ja koht
}

Wilbert M. Gesler

\section{Sissejuhatus}

Tervishoiu keel ekasutuse tähtsuse kohta on palju tõendeid. Paraku on suhteliselt vähetähel epanu pööratud kohale, kus keelt kasutatakse, kuigi tundub, et näiteks asjaolul, kas patsient räägib arstiga privaatselt tema kabinetis või haigla rahvast täis üldpalatis, on suur mõju sellele, mida ja kuidas räägitakse. Seega pean oluliseks lisada seosesse keel-tervis ka koht, sest üks võimalus parandada arstlike konsultatsioonidetulemusi on valida sobivam koht või muuta teatud koha omadusi vastavalt vajadusele.

See artikkel näitab, et keelel on tähtis osa tervishoiu ühendamisel kohaga. Järgnev ei ole seose keel-tervis-koht empiiriline tõendamine, vaid pigem teoreetilisel earutlusel etuginev ja asjakohastenäi detega varustatud uurimus, mis sel gitab teema edaspidise käsitlemise potentsiaali. Kuigi artikkel ei oleotseselt üles ehitatud empiirilise analüüsi raamistikuna, sisal dab see siiski uuringu teostamiseks ja tulemuste sel gitami seks vajal ikku loogi list põhimõtet. Artikkel koondab ühiskonnateooria viimased seisukohad loomaks sünteesi arstliku konsultatsiooni kol mest omavahel seotud elemendist: keel est, tervisest ja kohast.

Siinkohal uuritakse kolme seost: tervis ja koht, keel ja koht ning keel ja tervis. Esimene neist, tervise ja koha seos on meie ajakirja lugejatel e tõenäol iselt juba tuttav ning sellel põhjalikumalt ei peatuta, kuigi kogu arutelu on sellega seotud. Keeleja koha seosest on pisut juttu 2. osas, et lugejale meenutada, kuidas üks mõjutab teist. Artikli põhiosa käsitleb tervishoius kasutatava keele tähtsuse uurimist. Seda seost on kirjanduses küll üsna põhjalikult vaadeldud, kuid need käsitlused ei pruugi olla kõigilelugejatel etuttavad. Seejärel vaadel dakse keel eja tervise sidemeid. Esiteks näidatakse, kuidas patsiendid ja arstid kasutavad arstlikel konsultatsioonidel sel gitavaid mudeleid (explanatory models), mis põhinevad tead-

http:/haldjas.folklore.ee/tagused/nr22/gesler.pdf 
Wil bert M. Gesler

mistele, need aga väljenduvad omakorda enamasti keeles. Teiseks vaatleme keel ekasutust meditsiiniga seotud olukordades, näidates, kuidas keel loob tähenduse oma vormide ja viiside kaudu, millega sedasama keelt edasi antakse. Kolmandas osas on arutelu keskmes tervishoius kasutatava keele võimu, domineerimise ja resistentsuse roll. Keele ja tervise osa lõpus vaatleme lähemalt arstlikke konsultatsioone endid, eriti seda, kuidas patsient ja arst teineteist mõjutavad. Kogu arutelu taustal tuleb koha tähtsus nii teoorias kui ka näidetes kord vähem, kord rohkem esile. Artikli viimane, teoreetiline osa keskendub täielikult kohale, selle seosele keeleja tervisega näitamaks, kuidas need kol m komponenti on tervishoius ühendatud. 9. osas tuuakse välja küsimused, mida tuleks uurida, kui vaadel dakse koha mõju arstlike konsultatsioonide keelekasutusele.

\section{Keel ja koht}

Kuigi tervishoi uteemalises kirjanduses seda kuigivõrd ei käsitleta, on tähele pandud, et inimesed kasutavad igas keskkonnas erinevat keelt ja nii spetsiifiline koht nagu arstikabinet (Todd \& Fisher 1993) või palat (Kearns 1991) määrab vestluse sotsiaalse konteksti. Teisisõnu, kohal on tähtis osa keele kujunemisel. Yi-Fu Tuan (1991) sõnastab asja ümberpööratult ja selgitab, kuidas keel, nagu ka materiaalne ümberkujundamine, loob koha. Muuseas näitab ta, kuidas kohtadel e nime andmine teeb need meilekodusemaks, kuidas müüdid tugevdavad sidemeid kohaga, kuidas nimetamine annab jõudu, kuidas keel võib mõne asja kõrval dada ning kuidas ta hoiab tähendust alal ja väärtustab seda. Seega näeme, et keel ja koht loovad pidevalt teineteist.

Vaadel gem sidet keele ja koha vahel erinevate teadlaste tööde põhjal, kes väidavad üldjoontes sama. Alan Pred (1989) rõhutab tavasituatsi ooni de ja jõuvahekordadega seotud lokaal se keel ekasutuse tähtsust. Ta leiab, et keel mõjutab lokaalsete praktikate, käitumiste ja rollide standardeid heakskiidu või kriitikaga. Lev Võgotski ja tema kaaslaste uurimus, mida kirjeldavad Dorothy Holland ja J aan Valsiner (1988), näitab, kuidas sümbolid on vahendajateks meele (kultuuriliste teadmiste hoidja) ja keskkonna (kuhu kuulub ka koht) vahel. I nimesed tõlgendavad kontekste ja kasutavad vahendavaid mehhanisme sobivate kultuuriliste mu- 
Wil bert M. Gesler

delite (nt meditsiinistumise) alusel, kusjuures keel on prototüüpne vahendusmehhanism. Erialane sõnavara, mida D. Holland ja J . Valsiner vaatlevad (nt meedikute släng), on käesol eva artikli seisukohalt eriti huvipakkuv. Ka Robert Mugeraueri (1985) ideed on asjakohased. Ta sel gi tab, kuidas inimese teadmised keskkonna või koha kohta tulenevad eel nevast kogemusest ja kuidas need mõlemad, nii teadmised kui ka keskkond, tulenevad keelest. See tähendab, et keel aitab keskkonnal areneda. Lisaks sellele toovad kohalikud murded esile kohaliku keskkonna eripära. Seega peame selleks, et aru saada, kuidas inimesed tõlgendavad oma lähikeskkonda ja sealseid kohti, oskama kohalikku keelt.

\section{Seletuslikud mudelid, teadmised ja keel}

\subsection{Seletuslikud mudelid}

Erinevates ühiskondades ja ka ühe ühiskonna sees on käibel erinevad uskumused selle kohta, mis põhjustab haigusi ja kuidas neid ravitakse. Arthur Kleinmann (1978) nimetab selliste uskumuste kogumeid sel etusl i keks mude iteks (explanatory models) ja sel gitab, kuidas teatavasse olukorda sattunud (nt patsiendid ja arstid) toovad arstlikku konsultatsiooni kaasa erinevaid, tihti vastuolulisi mudel eid. Sel etuslikke mudel eid õpitakse sotsialiseerumisekäigus ja need loovad aluse kogemuste tõl gendamiseks. Arstlikul konsultatsioonil osalejad usuvad, et nad "teavad" teatud asju hai gusest ja tervisest. Näiteks usaldavad inimesed, keda on tugevasti mõjutanud biomeditsiini mudel, tingimusteta arsti ettekirjutatud ravimeid ja järgivad vastuvaidlematult ravirežiimi. Inimesed, kes usuvad humoraalmeditsiini, otsivad "tuliseid" või "külmi" (dieet)ravivõimalusi.

Seletuslike mudelite põhimõte on sarnane kultuurimudel itele, mis on üldtuntud ja endastmõistetavad maailmamudelid (Quinn \& Holland 1987: 4), nagu näiteks biomeditsii nilise või humoraal ravi mudel. Nii seletuslikud kui ka kultuurimudelid on selgelt seotud sotsiaaltervishoius tunnustatud teadusliku arusaamaga, et mõisted haigus ja tervis on sotsiaalsed tõlgendused (Turshen 1977; Waitzkin 1981). See tähendab, et halva ja hea tervise definitsioo- 
Wil bert M. Gesler

nid, nagu ka tervisega seotud uskumused ja käitumine kujunevad sotsiaalsete suhete põhjal. Eriti tugevasti on tervishoiusüsteemi mõjutanud biomeditsiiniline mudel.

\subsection{Teadmised}

Kultuurilised ja seletuslikud mudelid, mi da kasutatakse meditsiiniga seotud olukordades, tuginevad teadmistele. Käesoleva artikli eesmärgi huvides on vaja välja tuua neli olulist seisukohta. Esiteks, teadmised on subjektidevahelised, s.t need sisal davad inimese suhteid teistega (Game 1991). I nimesed vahetavad suhel des pidevalt teadmisi, seda tehakse ka arsti vastuvõtul. Teiseks on teadmised seotud ühe kindla olukorraga, s.t uskumused tuginevad tavaliselt teatud aega ja kohta isel oomustavatele ideedele ning kultuurimudelitele (Pile \& Thrift 1995). Näide:

See, et mei esotsi aal sed ja evol utsi ooni lised teadmised loomadest, hominiididest (iniml astest) ja meist endist on arenenud funktsionalistlikes ja kapital istli kes majandustermi nites, e ole looduseeksitus (Haraway 1991: 42).

Kui teadmised on seotud ol ukorraga, on selge, et loeb ka ajal ool ine kontekst, ning seega või vad need muutuda. Kolmas seisukoht on, et inimene võib saada maailmast otseseid, vahendamata teadmisi, et ta võib "rääkida tõde" millegi kohta (Fox 1993a). Nagu näeme all osas 5.4, on see seisukoht vaieldav.

\subsection{Keel ja diskursus}

Neljas seisukoht, mis vajab esiletoomist, on see, et teadmisi väljendatakse tihti keeles või diskursuses. Eriti selgelt väljenduvad sõnades tervise sel gitavad ja kultuurilised mudelid, mis tähendab, et hoolikas keeleanalüüs võib aidata neid rekonstrueerida (Quinn \& Holland 1987). M editsiinilisel diskursusel on mitu autorit. Biomeedikutest arstide diskursus on mõistagi sageli domineeriv, kuid võhikud ja meedia üritavad jätta valdavaks selle, mida nemad kasutavad. Teadmisi väljendades keel tingimata kategoriseerib reaal sust, kujundab seda ümber, moonutab ja paiskab segi. Seega: 
Wilbert M. Gesler

[---] on vähk, AIDS ja teised haigused muudetud diskursuse kaudu DNA, protei ini jt bi ol oogilistemudel itekul tuurilisetähendusega häl beks: AIDS on katk, vähk kuratlik vihavaenlane, kellevastu tul eb või del da (Fox 1993a: 3).

Keel on ka selle tõttu tähtis, et teda kasutatakse tihti inimeste veenmiseks ja nende arvamuste muutmiseks (Pile \& Thrift 1995).

\section{Keele kasutamine meditsiiniga seotud olukordades}

\subsection{Keel loob tähenduse}

Keel, mi da kasutatakse sel etuslike ja kultuuriliste mudel ite väljendamisel, on oluline, sest see edastab inimestele tähendusi. Näiteks võib see, kas arst kasutab konsultatsioonil rahulikku, neutraalset või ranget keelt, mõjutada ravi kulgu. Meedikute släng ja terminid, mis ei kuulu patsiendi sõnavarasse, võivad põhjustada ärevust ja segadust. Kuid keelt võib kasutada ka positiivselt, et muuta patsiendi suhtumist ja aidata kaasa paranemisele.

Üks võimalusi, mille abil inimesed toovad oma ellu tähendusi, on rituaalid, mis ülistavad, hoiavad alal ja uuendavad maailma (Helman 1994a). Need aitavad ka stabi liseerida inimestevahelisi ning inimeste ja keskkonna (sh spetsiifiliste kohtade) ning inimeste ja ülel oomul ike jõudude vahel isi suhteid. Stanley J. Tambiah (1968) sel gitab, kuidas kasutatakse sõnu rituaalsete muudatuste korral, näiteks ravitseremooniates. Arstid kasutavad rituaal seid väljendeid (nt sa saad terveks; seevõtab ainult aega), mida patsiendid ootavad, ja võivad niimoodi aidata kaasa nende paranemisele. Õpinguteajal kool itataksetulevasi arste kasutama rituaal set keelt, mis avab neile juurdepääsu privilegeeritute meditsi inilisele kultuurile (Atkinson 1995).

Reneé R. Anspachi järgi on haigusjuhtude esitlused kedelised rituaalid, milleabil arstid õpivad ja jõustavad meditsiinimaailma põhilisi uskumusi ja väärtusi (Anspach 1988: 357). Nad näitavad haiguslugude kaustu, milles on sageli kasutatud teatavaid kindlaid sõnu ja väljendeid, süntaktilisi struktuure ja sarnast ülesehitust. USA katoliiklastest nelipühilastetervendusrituaaleuurinud Thomas 
Wil bert M. Gesler

J. Csordas (1983) leidis, et paranemine sõltub tähendusrikkast ja veenvast vestlusest, mis muudab ehk kujundab patsienti ümber. See ümberkujundamine ei pruukinud ilmtingimata kaotada sümptomeid, küll aga võis muuta patsiendi arusaamist haigusest või koguni tema elustiili. Tervendusprotsessi kaasatud rituaalnekeel, gl ossol aalia (rääkiminekeel es, kus mõttetus purustab normeja loob uut liiki tähenduste võimaluse) ning deemonite nimede lausumine kehastavad afektiseisundit ja käitumisviise, mille abil püütakse deemoneid välja ajada.

\subsection{Meditsiinilise keele vormid}

Peame hool ega jäl gima keelt, mi da inimesed kasutavad meditsiiniga seotud olukordades. Näiteks teeb H oracio Fabrega (1980) vahet meditsiinilisel ja sotsi ofenomenol oogilisel keel el. Et esimest kasutavad biomeedikutest arstid ja teist patsiendid, on nende suhtlemine tihti keeruline. Arstid keskenduvad enamasti haiguse erialastele üksikasjadele, patsiendid aga haige ol emi sele, selletähendusele ja kogemusele. See tähendab, et nad kasutavad erinevaid seletuslikke mudeleid (Helman 1994b). J ocelyn Cornwell (1984) osutab raamatus Hard-earned Lives (Visalt kättevõidel dud elud), et tervise valdkonnas käibivad nii avalik kui ka isiklik diskursus. See on hoiatus, et empiiriline uurimine nõuab tungimist isikliku keeleni. Lisaks võib arstide ja võhikute keel ekasutus tervisest rääkimisel aja jooksul muutuda (Foucault 1991).

Meditsiinis kasutatava keele üks olulisi vorme on märgistamine Stephen J. Gould (1990) selgitab, kuidas keel kategoriseerib, eral dab, tekitab rivaliteete ja hei dab üleliigse kõrvale. Näiteks on nii metadoon kui ka heroiin opiaadid, kuid esimeneneist on USAs seaduslikult kasutatav ravim, teine aga keelatud narkootikum. Eri ühiskonnad märgistavad haigusi ja nende põhjusi erinevalt, mis ilmselt mõjutab nende ravi. Et meie kasutame rahvusvahelise hai guste klassifikatsiooni (RHK) koode ja diagnostikapõhiseid gruppe (DRG =diagonostic related groups), tuleneb biomeditsiinilisest mudel ist ja rõhuasetusest bi ol oogi listel e süsteemi dele. E rinevalt meist teevad Keenia kambad haigustel vahet algpõhjuse, ravimooduse, haiguse iseloomu ja haigestunute tunnuste järgi (Good 1987).

Kindlasti mõjutab ravimisviisi ka see, kui das patsiente märgistatakse. Üks uurimus, milles vaadel di juhuslikult valitud kirurgili- 
Wil bert M. Gesler

si patsiente, sedastas, et neid kirjeldati kas tavaliste, suhteliselt tavaliste või kõrval ekal duvatena (Lorber 1975). Robin J effrey (1979) täheldas, et kolme haigla traumapunktides liigitas personal haigeid "headeks" meditsiinilistetunnuste (s.t arstid võisid nende peal oma oskusi harjutada) ja "hal badeks" sotsiaal setetunnuste (s.t patsient oli purjus või narkouimas) al usel. "Halbu" patsiente nimetati näiteks dross 'jätis', dregs 'saast' ja rot 'mõttetu (mees)'. Ameerika meedikute ringkondades on üldlevinud patsiendi nimetamine gomeriks (Leidermann \& Grisso 1985). Seda sõna (mis või b viidata seriaalikangelasele Gomer Pyle'ile või fraasile go out of my emergency room 'käi välja minu kabinetist') koos sellistega nagu crock 'kronu, sant' ja gork 'krogi' kasutavad peamiselt residendid patsiendi kohta, kellega on raske hakkama saada ja kes seega panevad kahtluse alla nende kompetentsuse.

Märgistamine tuleb mängu ka teatud kohtade nimetamisel. Haigla mingi koha nimetamine hullupalatiks võib sellele märgi külge jäta. Ruumi nimetamine J onesi Memoriaalsalongiks võib viidata poliitilise võla tasumisele. Tähendus on isegi sellel, kuidas inimesed nimetavad teatud hai gust erinevates kohtades. Nii või b arst patsiendiga oma kabinetis rääkides kõnel da südamerabandusest, kuid operatsioonisaalis kasutada juba väljendit müokardi infarkt.

\subsection{Kuidas keelt edasi antakse?}

Arstlikel konsultatsioonidel kasutatavat keelt tuleb kuulata tähelepanelikult, sest see või beenelt edasi anda seda, mida inimesed on tegelikult mõtelnud. Selleks tuleb peatuda kahel peamisel võimalusel, mille abil saab uurida, millist teavet keel edastab. Esiteks võib keelt uurida nelja m-tähega al gava mõiste - metafoori, mude li, metonüümia ja müüdi - abil. Metafoorid võimal davad luua ske maatilisi kujutisi ehk mitmetähenduslikke vaimseid pilte sellest, mida inimesed on mõelnud või üritanud öelda (Quinn \& Holland 1987). Biomeditsiinis kasutatavad põhilised metafoorid keskenduvad kehale kui biokeemilisele mehhanismile, mis on toodud arsti juurde parandada. Sellised metafoorid kinnitavad biomeditsiini ratsionaalsust, eitades samal ajal haiguskogemusetähendust patsiendile (Kirmayer 1988). Susan Sontag (1978) osutab, et kui inimesed räägivad vähist, kasutavad nad enamasti keelt, mis viitab sotsiaalsele hälbele, sotsiaalsele ülekohtule, poliitilisele korruptsioonile, 
saatusele, katastroofile ja kurjusele. Metafoorid, mida inimesed kasutavad oma hai gusest rääkides, võivad paljastada mõndagi nende isiksuse ja suhete kohta. Näiteks peab mõni ägeda seljavaluga mees end argpüksiks või sel grootuks, teine patsient väljendab tülgastust enda vastu haisvate lagujääkide metafoori des (Kleinmann 1988).

Mudelid on metafooride süsteemid, mida kasutatakse samuti reaalsuse sel etamiseks. Tabava näite mudelist toobJ oseph William Bastien (1985), kes kirjeldab, kuidas Boliivia Andides elavad Qollahuaya indiaanlased modelleerivad inimkeha oma loodusliku keskkonna järgi. Metonüümiad määratlevad ainest mingi oma elemendi kaudu (Quinn \& Holland 1987). Teatud alamkategooriaid võetaksekui tüüpilisi, stereotüüpilisi või ideaalseid ja kui mõni teine alamkategooria kaldub neist kõrvale, peetakse seda valeks. Näiteks on paljud inimesed veendunud, et heteroseksuaalsus on ainuke õige seksuaal suhe, ja peavad seepärast homoseksuaalsust häl beks. Müütekasutab ühiskond maailma sel etamiseks inimeste õigeks peetava käitumise mudelite loomiseks. J ames Dow (1986) seletab, kuidas religi oossed tervendajad, šamaanid ja psühhoterapeudid kasutavad müüte ravimisel ja toob näite šamaanist, kes kasutab müüti kangelastest, kes võtavad ette raske teekonna, et aidata naist raske sünnitusejuures. Mõned platseeboravimid (raviva toimeta kontroll preparaadid) on efektiivsed, sest inimesed usuvad müüti, et ravimid, mille on välja kirjutanud tunnustatud arstid, aitavad (Frank \& Frank 1991).

Teine keel eline vorm, mida tihti kasutatakse teadmiste edasiandmiseks, on jutustus (story). Arthur Kleinman kirjutab oma raamatus The IIIness Narratives: Suffering, Healing and the Human Condition (1988): räägi meile, kuidas on elulised probleemid tekkinud, neid juhitud ja neiletähendus antud - see paljastab ka kultuurilised väärtused ja sotsiaal sed suhted. Patsiendid kasutavad narratiivi oma isikliku haiguskogemuse korrastamiseks. Arstid, kes kasutavad jutustusi omavahel patsi entidest rääkides, teevad seda enamasti müütiliste lugude ja moraalijuttude vormis (Atkinson 1995). J utustamisenäitena kirjel dab Carde Cain (1991), kuidas Anonüümsete Alkohoolikute (AA) liikumises osalejaid julgustatakse jutustama oma kogemustest ja kuulama teiste lugusid, et mõista oma probleemeja neist üle saada. J utustades võtavad nad ülekultuurimudelid, mida AA liikumine soovitab kasutada, et identifitseerida ennast kui ravimatuid al kohoolikuid, kes saavad ennast 
Wil bert M. Gesler

aidata ainult millegi endast vägevama (nt kõrgema autoriteedi) poole pöördumisega. C. Cain lindistas lugusid, mis jutustati kolmes keskkonnas - aruteludel, vestlusringides ja intervjuudel. Üks sedastusi oli, et need lood, mida räägiti arutel udel, olid pikema jutustuse lühivariandid.

LauriePrice (1987) kuulas õnnetuslugusid (mi sfortunetales) haigustest, mida rääkisid Ecuadoris Quitos peamiselt mestiitsidega asustatud äärelinna elanikud. Ta väidab, et lood haigustest

[---] on endassekodeerinud põhjusi sel gitavaid kultuurimudeleid, laial dasi teadmisi sellekohta, kuidas hai gusekorral õi gesti käituda, ja suurt hulka kultuurilisi teadmisi raviviisidest ja ravijatest (Price 1987: 313).

L. Price leiab, et jutustused haigustest vahendavad kasulikku eriteavet, aitavad inimestel täiustada oma haigusteooriaid, rõhutavad jutustaja abistajarolli ning tugevdavad rääkijate ja kuulajate vastastikust toetust.

Nii Panama Cuna indiaanlaste kui ka Malaisia malailastest rahvaarstid kasutavad sünnituslugusid selleks, et aidata naist raskel sünnitusel (Laderman 1987). Oma töös kasutavad ravijad polüsee miat (s.t nende sõnadel on palju tähendusi ) ja multivokaal sust - seega on nende sõnadel tähendusvarjundeid naisteelu erinevate aspektide puhuks. Kuna juttudes kasutatavaid metafoore leidub ka igapäevases keeles, on naistel juba eelsoodumus omistada neiletähendusi. Seega võivad ravitsejate sõnad tekitada platseeboefekti.

\section{Võim, dominantsus ja resistentsus}

\subsection{Võim, teadmised ja keel}

Sotsiaalteadustes räägitakse liigagi tihti või must, mis saavutatakse nii teadmiste kui ka keele ehk diskursuse kaudu. Teadmised ja diskursus ühest küljest ning võim teisest küljest toetavad üksteist. Need, kellel on teadmised, kasutavad neid oma võimu suurendamiseks, need, kelle käes on või m, võivad öel da, mis on teadmised või tegelikkus (F ox 1993a). Võim tuleneb tihti väidetest, et diskursus ja teadmised on ratsionaalsed ja teaduslikud ehk esindavad tõde (Boyne 1990). Üks kindlamaid võimalusi võimu saavu- 
Wil bert M. Gesler

tamiseks diskursuse kaudu on korrata, et teadmised on muutumatud ja kehtivad kõigis olukordades. Kordamine (rituaali tähtis aspekt) on vaieldamatult vajalik asjatundlikkuse kinnitamiseks (Fox 1993a).

Diskursusest või teadmistest tulenevat võimu kasutatakse juhtimiseks, kamandamiseks ja liidrikoha kättevõitmiseks. Teadus on kõige tähtsam näideteadmistest ja/või diskursusest, mida kasutatakse liidrirolli saavutamiseks ehk domineerimiseks.

Teadus koosneb teadmistest ja võimust. Meie ajal piiritlevad loodusteadused inimese koha looduses ja ajaloos ning määravad ühiskonnas domi nerimisevõi mal used (Haraway 1991: 43).

Loodusteadused, seal hulgas biomeditsiin domineerivad teatud rühmades (nt naised, vaesed), kinnitades, et erinevused on loomulikud, määratud, vältimatud ja seega moraalsed (Haraway 1991: 8).

\subsection{Võim ja koht}

Käesoleva artikli üldeesmärgi seisukohalt on vaja ka lühidalt märkida, et võim avaldub kohtades. Arutluses võimu üle uurib Michel Foucault võimu mõju kohtadele, kus see tegelikult ilmneb, mitte lai emas ja abstraktsemas skaalas, nagu näiteks riik või seadused. Ta ütleb, et võim lokaliseerub indiviididele avaldatud mõju kaudu (Fox 1993a). Ka J acques Derrida tegel eb regionaalse ehk lokaalse tasemega.

Ta e ol ekotkas, kes lendab kõrgel maastiku kohal ja kaardistab seda. Tema mõtl emi ne sarnaneb pigem üleannetu määrdeõliga, mis voolab uuritavateteksti devahel ja üritab pääseda pragudekaudu senitundmatutessekohtadesse(Boyne 1990: 91).

Võim ilmneb ka meditsiiniga seotud olukordades, s.t meditsiiniga seotud toimingutes ja puhtakujulises meditsiinikeskkonnas.

\subsection{Võim tervishoius}

Meditsiin kui teadusala on oma olemuselt nii teadmiste kogum kui ka või mu allikas (F ox 1993a). Donna J . Haraway ütleb: 
Wil bert M. Gesler

Biomeditsi inilisekel evõim koos oma suurepärasteartefaktide, kujundite, ül esehituse, sotsiaal sete vormideja oskussõnadega on miljonite inimeste ebavõrdse haigus- ja surmakogemuse kujundamisel sotsi aalnetõsi asi, mis tuleneb pi devatest heterogeensetest sotsiaal setest protsessidest (Haraway 1991: 203-204).

Võim ei puudu ka tervishoiust, vaid on selle osa, mis isel oomustab abistaja ja abistatava suhteid. Selle idee illustreerimiseks vaatleb Nicholas J . Fox (1993b), kuidas kirurg pärast Iõikust patsiendiga räägib. Et sellised patsiendid on elanud ülekaks šokki, ühe narkoosi ja teise lõikuse enda tõttu, ei tunnenad end enamasti kuigi hästi ning kirurg peab neid veenma, et nad kindlasti paranevad ja et tema ei eksinud oma prognoosides, selleks et ei väheneks ta enda autoriteet ega kontroll olukorra üle. Näiteks pakub ta patsiendile haiglast väljakirjutamist kui kingitust, mis näitab, et patsiendiga on kõik korras. Paljud uurijad rõhutavad tervishoius kasutatava domineeriva suhte kahjulikkust. Teisalt vaidleb Per Maseide (1991) neilevastu, väites, et võim on tõhusa meditsiinipraktika puhul hädavajalik. See tähendab, et biomeditsiinilise hariduse saanute puhul on nõutavad asjatundlikkus ja autoriteetsus ning patsientide ja arstide kokkupuutel on sümboolse kapitali ebavõrdne jagunemine vältimatu.

Viimased uurimused on näidanud, et meditsiini diskursus keskendub inimese kehale, mida saab tõl gendada nii biol oogi liselt kui ka kultuuriliselt ja sotsiaalselt (Fox 1993a, Pile\& Thrift 1995). Diskursused n-ö kirjutataksekeha pinnale, nende abil keha märgistatakse ja ta saab tähenduse. Seega muutub keha tekstiks, mille abil saavad nähtavaks tema kohta loodud diskursused. Selliseid tekste kirjutavad ja loevad erinevad eksperdid, seal hulgas arstid, kosmeetikud, spordiinstruktorid või armastajad (Fox 1993a). N. J. Fox (1993a) arutleb ka kirurgide ja anestesioloogide tavalise konflikti üle patsiendi keha kohal: kirurg tahab, et haige kude eemaldataks või vähendataks seda nii palju kui võimalik, anestesioloog aga tahaks hoiduda kehale liiga suurt psühhol oogilist stressi tekitamast, et paranemine oleks kindel ja kiirem.

Sõnad kehastavad tihti võimu, sest inimesed usuvad, et sõnad võivad materialiseeruda. Näiteks seostub Põhja-I taalias vähk surma, kannatusteja lootusetusega (Gordon 1990). Paljud inimesed usuvad, et kui arst, sugulane või sõber ütleb patsiendile haiguse nime, siis tähendab see patsiendi surmamõistmist, sest nimetamine kut- 
Wil bert M. Gesler

sub nimetatu kohaleja suleb lootusele ukse. Reneé R. Anspach (1988) näitab, et see, kuidas arstid haigusjuhte esitlevad, aitab neil hinnata oma võimu patsientide üle. Esitluse ülesanne on 1) eraldada bioloogilised protsessid patsiendist või muuta need umbisikuliseks, 2) passiivi kasutamise kaudu vähendada arsti vastutust ja neutraliseerida vigu, 3) käsitleda meditsiinitehnoloogiat kui vahendit ja 4) suruda maha patsiendi kaebused. On loodud epistemoloogiline hierarhia, milletipus on diagnostika (see toob esileja näitab), järgnevad arstlikud läbivaatused (arstid märgivad üles ja panevad tähele) ning kõige all on patsiendid (kes annavad teada või salgavad). Oma uuringus viiest New J ersey agulis rakendatavast alternatiivsest põetamispraktikast (kristlik, mediteerimisele ja inimvõimetele tuginemine, metafüüsiline, okultneja eklektilinening oskustekeskne) leidis Meredith B. McGuire (1983), et keel on võimu allikate muutmise ja seega ka ravi efektiivsuse põhikomponent. I nimesed usuvad, et J eesusenimi, mantra lugemine või fraasi "mina olen" pomiseminetekitab positiivset, tervendavat energiat.

\subsection{Resistentsus ja erinevus}

Nägime, et ülemvõimu ja liidrirolli saavutamiseks kasutatav keel saavutab oma võimu, väites, et ta kõneleb tõtt. Sellele väitele on siiski vastu vaiel dud. Ferdinand de Saussure märkis, et sõna ja sellega edastatava idee, seega tähistaja ja tähistatava vahel on vaid meelevaldne seos. Selle tulemusena on keel tihti kahemõtteline; seda või b mitmeti tõl gendada ja selle tähendusi kahtluse alla seada (Boyne 1990). J . Derrida viitas väitele tõe rääkimisest kui kohal olekust, mis väljendab ideed, et mingi asi saab olla olemas ainult siis, kui on olemas keegi, kes on selle olemasolust teadlik. Seda seisukohta tuntakse logotsentrismina. Läänemaailma teadus kaldub tihti logotsentrismi või väidab, et see on juurdepääs reaalsusele ilma igasuguste vahendusprotsessideta, mis võivad fakte moonutada (Boyne 1990). J . Derrida tõendab siiski, et väited ol emasolu kohta on ekslikud ja need ei moodusta teadmiste alusmüüri.

Suhtlemisele on suurimaks takistuseks asjaolu, et erinevad inimesed kasutavad sõnu erinevates olukordades erinevas tähenduses. J . Derrida pidas väga oluliseks erinevuste analüüsi ja konstateeris, et olemasolu kinnitus on tihti kasutusel vaid selleks, et kõrvaldada erinevused (Fox 1993a). Näiteks kui patsiendi ja arsti vest- 
Wil bert M. Gesler

Iuses mainitakse sõna "vähk", võib arst mõelda sellest, kas lõikus on vajalik, patsient aga tunda hirmu valu ja radikaalsete elumuutuste ees. Lisaks saavad sõnad tähenduse nii sellepärast, et nad erinevad teistest sõnadest, kui ka tähistaja ja tähistatava suhete al usel. Kui inimene mõtleb vähist, si is võrdleb ta seda mõttes teiste sõnade või fraasidega, nagu näiteks "südamehaigus".

Arusaam, et ülim tõde on tabamatu ja kindlasti ka võimatu, võib olla meeleheite ja tegevusetuse põhjus. Teisest küljest annab see võimaluse kuulata muid arvamusi ja pöörata tähelepanu sellele, mida on öelda madalamal positsioonil olevatel inimestel (Boyne 1990). Domineerivale diskursusel e vastu seismiseks on kasutatud kaht strateegiat. Dekonstruktsioon vaatleb tekste ehk diskursusi ja üritab uurida, kuidas teadmiste hulgas lei duvad ol emasolu kinnitused ehk tõed tekivad, ja vaidleb siis neile vastu (Game 1991). Intertekstuaal sus osutab strateegiale, mille puhul uuritakse erinevaid diskursusi üksteise suhtes, inter preteerides tekste teiste tekstide valguses. Seegi praktika võimaldab saadud tarkuse kahtluse alla seada ja alustada diskussiooni teistsugustearvamustega. Paul Atkinson (1995) toob näite, et kui arstid kõnel evad omavahel patsientidest, on nad tihti eriarvamusel. Õpitud teaduslik lähenemine erineb kliinilisest kogemusest, röntgenikiired räägivad teist juttu kui koeuuringud mikroskoobi all. Töö "erinevuste mänguga" võimal dab vastu seista suhetele, mis põhinevad täielikult domineerival hierarhial või vastupanul ning asendada need võrdsusel ja koostööl põhinevate suhetega (Haraway 1991). Kui Sue Fisher (1991) võrdles, kuidas õed ja arstid rääkisid naispatsientidega, leidis ta, et õed julgustasid vastupanu ja valikuvabadust ning andsid naistele "ruumi" end väljendada, arstid aga seda ei tei nud.

\section{Arstlikud konsultatsioonid}

Keele osa dominantsetes ja võimusuhetes aval dub sel gelt arstlikel konsultatsioonidel (Todd \& Fisher 1993; Fisher 1993b). On oluline märkida, et arstlikud konsultatsioonid toi muvad spetsiifilistes ruumides, näiteks arstikabinetis või haiglapalatis. Klassikaline näide tervishoiuvaldkonnast on arsti ja patsiendi "vestlus", kus mängu võivad tulla sotsiaalne staatus, teadmiste hulk ja soorollid (DiGiacomo 1987), kuigi on olemas ka teistsuguseid arstlikke konsultatsioone, nt arstide omavahelised (Atkinson 1995). Patsiendi ja 
Wil bert M. Gesler

arsti vastastikust mõju käsitlevad paljud autorid. Näiteks sisal dab Alexandra Orendas Toddi ja Sue Fisheri (1993) toi metatud väljaanne mitmeid uurimusi, mis käsitlevad selliseid teemasid nagu arsti ja patsiendi vahelised kultuurilised erinevused, kuidas meesarstid enamasti domineerivad naist küsitledes, võimalusi, kuidas naised saavad domineerimi sel e vastu seista ja kuidas vestl usi arstiga saab kasutada petmiseks. Elliot George Mishleri (1984) tähtsaim raamat keskendub sellele, kuidas analüüsida arstlikke küsitlusi kui diskursust, mis on tähendusrikas jutuajami nearsti ja patsiendi vahel (Mishler 1984: 7-8). Ta juhib tähelepanu sellele, et õpingute ajal räägivad arstid tavaliselt patsientidega haiglapalatis ja traumapunktis ning nad saavad õppi des vähe kogemusi, kuidas kasutada arstipraktikas vestlusi patsientide sisemaailmaga tutvumiseks.

Suhteid arsti ja patsiendi vestluses on tõl gendatud ja analüüsitud erinevatest vaatenurkadest. Anthony L. Suchman ja Dale A. Mathews (1988) vaatavad asja pigem positiivselt ja rõhutavad, et kontakt võib olla raviv, sest see rahul dab inimese põhivajadust tähelepanu järele. David Tuckett koos kolleegidega (Tuckett et al. 1985) tõstatab ka õige suhtlemise väärtuse teema, kuigi autorid teadvustavad endale ka loomuliku võimuvõitluse probleeme ning patsiendi ja arsti koostöö emotsi onaalset konteksti. Autorid leiavad, et arsti vastuvõttudel kulutatakse patsiendi mõtetele vähem aega kui arsti omadeleja paljud arusaamatused tulenevad vastandlikesel etuslike mudelitekasutamisest. Cecil G. Hel man (1994b) leiab samuti, et arstid keskenduvad rohkem haiguse üksikasjadele ja biomeditsiinilise mudeli "kultuurile", samas kui patsiendid on rohkem huvitatud haigusest ja selle tähendusest ning läbi elamistest. C. G. Helman ütleb, et arstid tõlgendavad patsientidekaebustekelt sageli valesti. Seda üsna pessimistlikku vaatepunkti arsti ja patsiendi kokkupuute teemal on arendanud edasi Howard Waitzkin (1989), kes väidab, et arstid väljendavad sel liseid ideol oogiaid, nagu töö tähtsus, perekondl ikud väärtused ja tootmisega seotud sotsiaalsed suhted, mis toetavad kehtivat sotsiaalset süsteemi (nt julgustavad nad mehi uuesti tööle asuma ja naisi koju jääma). Arstid katkestavad patsienti küsitluste ajal sageli strateegilistel eesmärkidel, et säilitada oma liidriroll, jätta vestlusest välja tähtsaid kontekstuaalseid küsimusi, panna kiiremini diagnoos ja määrata ravimid ning jätta patsiendile ravi osas vähe valikuid.

Eriti kasulik on vaadel da arstlikku konsultatsiooni draamana, milles osalevad patsiendid, arstid, õed ja muud tegelased. Kui ars- 
Wilbert M. Gesler

tid räägivad omavahel patsientidest, võib näiteks üht süžeeliini ja retoorilisi lauseid kasutada veenmiseks. Nende vestlus sisaldab konflikte, salapärasusi ja asjakohaseid tõiku (Atkinson 1995). N. J . Fox (1993a) ütleb, et arstid kasutavad rekvisiite - ekraanid, valged kitlid, märkmed - liidrirolli kindlustamiseks. J oan P. E merson (1970) kirjeldab günekoloogilist läbivaatust kui etendust, mis paneb proovile osalistenäitlejavõimed. Konfliktis on sellised osalised nagu patsient kui objekt meditsiinilises tähenduses, inimlik vajadus kohel da patsienti kui inimest ning vaagnapiirkond kui inimkeha spetsiifiline osa. Arst peab kasutama keelt, mis on üheaegselt autoritaarne, rahustav ja ilma seksuaal se kõrval tähenduseta, patsient aga balansseerima kombekuse ja siivutuse piiril.

\section{Keel, tervis ja koht}

Varasemate arutl uste põhjal hakkasime nägema, et keel, tervis ja koht on omavahel seotud. Näiteks panime tähele, et meditsiinilised teadmised on seotud kohtadega ja et arstlikud konsultatsioonid toi muvad teatud kindl ates kohtades. Rääkisi meka mõnedest spetsiifilistest näidetest, kus koht oli oluline faktor. Märkisime, et Anonüümsete Alkohool ikute liikumises osalejad jutustasid oma lugusid erinevates kohtades (Cain 1991) ja haiglaruumidele saab märgistamise abil anda lisatähenduse. Thomas J . Csordas (1983) teeb põgusa viite kohale, kui mainib katoliiklastest nelipühilaste "ravimisruume" - nende ruumi de atmosfäärist ja inventarist tahaks rohkem teada saada. Reneé R. Anspach (1988) märgib, et patsiendi ütlustega arvestamine on aja jooksul asendunud arstide tehtud kliiniliste uuringute ja meditsi iniaparatuuri usal damisega, nii nagu patsi endi ja arsti kokkupuutepunkt on nihkunud kodust haiglasse ja laboratooriumi. Siiski on kirjanduses vähe viiteid keel eleja tuuakse sel gesõnaliselt esilekoha tähtsus. J ärgnevalt alustame selleteemaga.

Tervishoiuasutusteruumide spetsi ifil ised omadused, nagu seinte värv, valgustatus ja sisseseade paigutus, võivad mõjutada seda, mida öeldakse ja kuidas seda interpreteeritakse. Põhitees on, et vahetu füüsiline ümbrus mõjutab inimeste keelekasutust (Bettel heim 1974; Canter 1986). Kui palatis tõmmatakse näiteks kardinad voodi ette, on see ainult privaatsuse teesklemine (Kirmayer 1988). Peaarsti kabinet loob unikaalse atmosfääri teaduslike raa- 
Wil bert M. Gesler

matuteja ajakirjade, perepiltide, arvuti, maastikumaalide ja muu sellisega (Helman 1994a).

Biomeditsiin on loonud haiglates ja kliinikutes rituaalsed ruumi d, mis on määratud teatud raviprotseduuride läbiviimiseks. Pearl Katz (1981) väidab, et moodsa haigla operatsioonitoas läbiviidavad hoolikalt viimistletud rituaalid, mida justkui rakendatakse operatsioonijärgsete nakkuste vältimiseks, aitavad kaasa ka lõikuse õnnestumisele. Kätepesu, operatsioonikitlite selgapanemise ja rangete toimingute kõrval, mida võetakse ette kirurgiriistadega, on keelel rituaalis samuti oluline osa. Sellistel sõnadel nagu "puhas", "must", "steriilne" ja "nakatunud" on operatsiooni eri etappides erinev tähendus. Arstid ja õed jäl givad rangelt ettemääratud reegleid selles osas, millal peab valitsema täielik vaikus (nt kui kirurg teeb esimese sisselõike), millal antakse lühikesi korraldusi (nt operatsiooni käigus), millal võib naljatada (nt kui suurem osa operatsi oonist on läbi ) ja millal operatsioonibrigaadi liikmed võivad lobiseda oma vaba aja veetmise kavadest. Operatsioonisaal on sel gesti eraldatud koht, kus saab teha ainult teatud asju ja rääkida kindlal ajal.

Kuigi kirjanduses on sellele faktile vähe tähelepanu pööratud, on mõnedes uuringutes sedastatud spetsi ifilisekeskkonna tähtsust seoses arstlike konsultatsi oonidega. J oel C. Kuipers (1989) väidab, et tähtis on uurida, kuidas meditsiinilised vestlused varieeruvad sõltuvalt keskkonnast (nt haiglaringkondades, surmatunnistustel, haiguslugudes ja arstide nõupidamistel). Oma günekol oogilisi läbivaatusi käsitlevas uurimuses märgib J oan P. Emerson (1970), et konsultatsioon toi mub spetsiaal ses läbivaatusruumis. Tähtis on selle koha si sustus - sei nakate, sisseseade, teistest eral dav ettetõmmatav kardin. P. Atkinson (1995) jälgis mitme nädala jooksul kolme hematol oogist kolleegi ühes USA idaosa suures õppehaiglas ja märkas, et nad käivad teiste arstide konsulteerimiseks väga paljudes eri ruumides. Huvitav oleks teada, kuidas need erinevad paigad mõjusid arstide ühistegevuse efektiivsusele.

Sue Fisher (1993a) kirjeldas arsti ja patsiendi vestlust teemal, kas emakas tuleks eemal dada või mitte, kahes haiglas, mis kuulusid üheülikooli suure õppehaigla reproduktiivmeditsiini instituudi koosseisu. Arstiteaduskonna kliinikus olid privaatneja avalik ruum eral datud, samuti ol id eraldatud läbivaatusruumid ja vastuvõtukabinetid. Munitsipaal haiglas sellist privaatsust ei ol nud. Arstiteaduskonna kliinikus töötasid reproduktiivonkol oogia õppejõud ja suurema osa patsiente suunasid sinna lähikonnas töötavad arstid. Mu- 
Wil bert M. Gesler

nitsi paal haiglas töötasi d residendid ja suurema osa patsiente suunasid sinna sotsiaalabiosakonnad või teised sotsiaal hool dussüsteemi kuuluvad haiglad. Vanemad, mehhiko või mehhiko-ameerika päritolu naised, kes moodustasid enamiku munitsipaalhaigla patsientuurist, said üldjuhul radikaalset ravi, erinevalt noorematest, valgetest naistest, keda raviti arstiteaduskonna haigl as konservatiivsete meetoditega. Teisisõnu, kahes erinevas kohas toimunud vestlustetulemused olid üsna erinevad. S. Fisher märgib, et arstid tegutsesid mõlemal juhul oma mängumaal, patsiendid aga olid sattunud võõrasse ümbrusesse.

\section{Koha mõju arstlikel konsultatsioonidel kasutatavale keelele}

Eelnev diskussioon andis empiiriliste uurimuste näi detel e tugineva teoreetilise aluse, mille abil saab uurida koha mõju arstlikel konsultatsioonidel kasutatavale keelele. Välja või b tuua järgmised punktid.

1. Erinevad inimesed tul evad arstlikulekonsultatsioonileerinevate seletuslikeja kultuuriliste mudel itega, mis tuginevad teadmistele ja aval duvad keeles või diskursuses.

2. Arstlike konsultatsioonide keelt saab uurida tähenduse loomise (s.t rituaalide), kasutatud väljendusvormi de (s.t märgistamise) või edasiandmise (s.t metafooride ja lugude) kontekstis.

3. Meditsiinilised teadmised ja keel on võimuallikad ja neid kasutatakse meditsiiniga seotud olukordades teiste kontrolli all hoidmiseks. Siiski võib võimusuhteid ka teisiti võtta, sest erinevused või vad paranemisel e hoopis hästi mõjuda.

4. Koht võib keele ja tervisega seostuda ruumi spetsiifiliste omaduste, rituaalseteruumideja erilise keskkonna või asukoha kaudu.

Kuidas saab neid tõdemusi kasutada empiirilises uuringus? Tuleb tunnistada, et see on üsna raske, sest keel on mitmeti tôlgendatav ja inimesed loovad ning vaidlustavad tähendusi suvalises sotsiaalses kontekstis. Pealegi sisalduvad igas arstlikus konsultatsioonis vähemalt järgmised tegurid, mill ega kaasnevad sõnamuutused: koht, isiksuse omadused, inimeste kehastatavad rollid, sel etuslikud mudelid, kasutatavad keelel ised stiilid ja vestluskaaslaste võimusuh- 
Wil bert M. Gesler

ted. Ü hes töös on võimatu analüüsida kõiki omavahel seotud tegureid. Seega ol eks soovitatav püüda vaadelda ainult mõnd arstlikel konsultatsi oonidel kasutatava keele aspekti, teisi samal ajal siiski silmas pidades. Kasutatav meetod peaks kindlasti olema kvalitatiivne (kõige sobivam on avatud lõpuga või pool struktureeritud vestlus) ja suutma analüüsida vestluses ette tulevaid mudelid või teemasid (vt nt Miles \& Huberman 1994). Nende üldiste mustrite ja teemade (nagu ka vältimatute isikupärade) interpreteerimine on mõistagi subjektiivne, kuid abiks võivad olla käesolevas artiklis kirjel datud teooriad.

J ärgnev küsimustik üritab vaadel da arstlike konsultatsioonide erinevaid tegureid, kusjuures ühisosana on neis kõigis vaatluseall koht. Oletagem näiteks, et viibime haiglas. Need kohad haiglas, mida ol eks huvitav uurida, on arstikabinet, õdede tuba, läbivaatusruum, nii üksik-kui ka ühispalat, traumapunkt, operatsioonisaal, koridorid, protseduuriruumid (röntgenikabinet jne). Arstlikel konsultatsioonidel osalejad on üld- ja eriarstid, õed, arstide assistendid, laborandid, farmatseudid jne. N endest kohtadest ja osal istest lähtudes võib esitada järgmisi küsimusi.

1. Millistel seletuslikel mudelitel põhinevat keelt kasutavad erinevad osalised ühes kindlas kohas?

2. Kuidas samad osal ised muudavad oma keel ekasutust erinevates kohtades? Näiteks, kas arst räägib patsiendiga haigusest ühtemoodi oma kabinetis, üldpalatis ja teel operatsioonile?

3. Millist rituaal set keelt kasutatakse haigla erinevates kohtades, s.t milliseid tüüpilisi sõnu ja fraase kasutatakse korduvalt tähendusteja suhete tugevdamiseks?

4. Kas erinevates kohtades kasutatakse erinevaid väljendusvorme? Kas patsiendid või arstid kasutavad sotsi ofenomenol oogil ist või biomeditsiinilist keelt ühes kohas rohkem kui teises? Kas arstid või patsiendid märgistavad üksteist erinevates kohtades erinevalt?

5. Kas keelt antakse erinevates kohtades edasi erinevalt? Kas on olemas erinevaid metafoore, mudeleid, metonüümiat või müüte, mis seostuvad teatud kindlate kohtadega? Kas näiteks traumapunktis töötavad inimesed teavad müütevarem nenderuumides toimunust? Kas patsient räägib oma haiguse lugu arsti kabinetis, läbivaatusruumis ja kirurgiapal atis erinevalt?

6. Kuidas mõjutab koht, kus arstlik konsultatsioon toimub, võimusuhteid? Kas mõnes kohas on arstil kergem oma autoriteeti 
Wilbert M. Gesler

maksma panna või patsiendil sellele vastu seista? Mida räägivad haiglapersonali vestlused erinevates keskkondades meile meditsiinitöötajatehierarhiast?

7. Kuidas erinevatehaiglaruumidenimetaminevõi uksesil did koridorides saavad erinevate haigl as viibivateinimestesilmis erineva tähenduse?

8. Kuidas mõjuvad osalistesuhtlemiseleruumideerinevad omadused? Kas on näiteks olemas sisustust või detaile (lilled, maalid), mis võivad suurendada või vähendada konsultatsiooni kvaliteeti?

Loomulikult on palju võimalusi, kuidas saab kohtade, osaliste ja meditsiiniga seotud olukordade kombinatsioone uurida - eespool välja toodud küsimused on ainult soovitused paljude võimaluste hulgast. Koha mõju määramiseks saab iga uurimus keskenduda üksnes väikesel e kohtade ja osaliste valimile. Kui jutt on vestluse paigast ja sellest, millised on selle paiga omadused, siis üldjuhul peetakse kohta selleks, mis määrab erinevused.

\section{Kokkuvõte}

Koha mõjust arstlikel konsultatsioonidel kasutatavale keelele on üsna vähe teada. Käesolev kirjutis juhib tähelepanu sellele, et sellistes olukordades on koht tähtis, ja kutsub üles uurima rohkem keele, tervise ja koha koosmõju. Kuigi arutleti ka terviseja koha ning keele ja koha seoste üle, oli põhirõhk siiski keele ja tervise seostel ning sellel, kuidas saab koht aidata paremini mõista keele ja tervise seoseid. Artikkel näitab, et on võimalik esitada teatud küsimusi, mis tuginevad kindlatele teoreetilistele al ustele. Kohauuringuid võivad toetada järgmised nähtused: (1) sel etuslikud mudelid, mille aluseks on teadmised ja mi da väljendatakse keele abil, (2) erinevad keelekasutusviisid arstlikel konsultatsioonidel ning (3) keele kasutamise võimal used võimu ja domineerimise väljendamiseks, aga ka vastupanu avaldamiseks.

Käesolevas artiklis käsitletud teemade edasineuurimineaitaks tervishoiusüsteemi parandada vähemalt kahel viisil. Esiteks annab teave koha rollidest meile sel gust, kus vestlused peaksid toimuma, et teabevahetus oleks või malikult tõhus ja konsul tatsiooni osapooled võrdsemas seisus. Uurimused peaksid näitama, kus 
Wilbert M. Gesler

on kõige parem öelda (või ütlemata jätta) teatud asju, mi da erinevad osalised räägivad erinevates kohtades, mida räägitakse erinevates keskkondades ja kus ilmneb dominantsus või resistentsus. Teiseks sel gitab artikkel, millal koha omadused võivad ravi positiivselt mõjutada. U urimused peaksid meile näitama, kuidas koha omadused parandavad või halvendavad arstlikekonsultatsioonide tulemusi.

\section{Tõlkinud Kristin Haugas ja Anne Kaaber}

Originaal: Gesler, Wilbert M. 1999. Words in wards: Language, health and place. Health \& Place5, Ik 13-25. Avaldatud Elsevieri loal.

\section{Kirjandus}

Anspach, Reneé R. 1988. N otes on the sociology of medical discourse: The language of case presentation. J ournal of Health and Social Behavior 29, Ik 357-375.

Atkinson, Paul 1995. Medical Talk and Medical Work: The Liturgy of the Clinic. London: Sage.

Bastien, J oseph William 1985. Qollahuaya-Andean body concepts: A topographical-hydraulic model of physiology. American Anthropol ogist 87, Ik 595-611.

Bettel heim, Bruno 1974. A Homefor theHeart. N ew York: Alfred A. Knopf. Boyne, Roy 1990. Foucault and Derrida:TheOther Sideof Reason. London \& Boston: Unwin Hyman.

Cain, Carole 1991. Personal stories: Identity acquisition and selfunderstanding in Alcoholics Anonymous. Ethos 19, Ik 210-253.

Canter, David 1986. Putting situations in their place. F urnham, Adrian (toim). Social Behaviour in Context. Boston: Allyn and Bacon, Ik 208-239.

Cornwell, J ocelyn 1984. Hard-Earned Lives: Accounts of health and illness from E ast London. London: Tavistock \& New York: Methuen.

Csordas, Thomas J . 1983. The rhetoric of transformation in ritual healing. Culture, Medicineand Psychiatry 7, Ik 333-375.

DiGiacomo, Susan M. 1987. Biomedicine as a cultural system: An anthropologist in the kingdom of the sick. Baer, Hans A. (toim). Encounters with Biomedicine: CaseStudies in Medical Anthropology. New York: Gordon and Breach Science Publishers, Ik 315-346. 


\section{Wilbert M. Gesler}

Dow, J ames 1986. Universal aspects of symbolic healing: A theoretical synthesis. American Anthropol ogist 88, Ik 56-69.

Emerson, J oan P. 1970. Behavior in private places: Sustaining definitions of reality in gyneacological examinations. Dreitzel, Hans Peter (toim). Patterns of Communication Behavior. New York: Macmillan Company, Ik 74-97.

Fabrega, Horacio jun. 1980. Disease and Social Behavior: An Interdisciplinary Prospective. Cambridge: MIT Press.

Fisher, Sue 1991. A discourse of the social: Medical talk / power talk / oppositional talk? Discourse and Society 2: 2, Ik 157-182.

Fisher, Sue 1993a. Doctor talk / patient talk: how treatment decisions are negotiated in doctor-patient communication. Todd, Alexandra Dundas \& Fisher, Sue (toim). The Social Organization of Doctor-Patient Communication. 2. tr. New York: Ablex Publishing Corporation \& Norwood, Ik 161- 182.

Fisher, Sue 1993b. Introduction. Todd, Alexandra Dundas \& Fisher, Sue (toim). The Social Organization of Doctor-Patient Communication. 2. tr. New York: Ablex Publishing Corporation \& Norwood, Ik 1-24.

Foucault, Michel 1991. The Birth of the Clinic: An Archaelogy of Medical Perception. London: Routledge.

Fox, Nichol as J . 1993a. Postmodernism, Sociol ogy and Health. Buckingham: Open University Press.

Fox, Nicholas J . 1993b. Discourse, organization and thesurgical ward round. Sociol ogy of Health and IIIness 15: 1, Ik 16-42.

Frank, J erome David \& Frank J ulia B. 1991. Persuasion and Healing: A ComparativeStudy of Psychotherapy. Baltimore:J ohns Hopkins University Press.

Game, Ann 1991. Undoing the Social: Towards a DeconstructiveSociol ogy. Milton Keynes: Open University Press.

Good, Charles M. 1987. Ethnomedical Systems in Africa. New York: Guilford Press.

Gordon, Deborah R. 1990. Embodying illness, embodying cancer. Culture, Medicineand Psychiatry 14, Ik 275-297.

Gould, Stephen J. 1990. Taxonomy as Politics: The Harm of False Classification. Dissent: Winter, Ik 73-78.

Haraway, Donna J . 1991. Simians, Cyborgs and Women:TheReinvention of Nature. London: Free Association Books. 


\section{Wilbert M. Gesler}

Helman, Cecil G. 1994a. Ritual and the management of misfortune. Helman, Cecil G. (toim). Culture, Health and IIIness. 3. tr. Oxford: Butterworth Heinemann, Ik 224-245.

Helman, Cecil G. 1994b. Doctor-patient interactions. Helman, Cecil G. (toim). Culture, Health and IIIness. 3. tr. Oxford: Butterworth Heinemann, Ik 101-145.

Holland, Dorothy C. \& Valsiner, J aan 1988. Cognition, symbols and Vygotsky's developmental psychology. Ethos 16, Ik 247-272.

J effrey, Robin 1979. Normal rubbish: Deviant patients in casualty departments. Sociology of Health and IIIness 1: 1, Ik 90-107.

Katz, Pearl 1981. Ritual in the operating room. Ethnology 20: 4, Ik 335-350.

Kearns, Robin A. 1991. The place of health in the health of place: The case of the Hokianga special medical area. Social Science \& Medicine 33, Ik 519-530.

Kirmayer, Laurence J . 1988. Mind and body as metaphors: Hidden values in biomedicine. Lock, Margaret \& Gordon, Deborah R. (toim). Biomedicine Examined. Dordrecht: Kluwer Academic Publishers, Ik 57-93.

Kleinmann, Arthur 1978. Concepts and a model for the comparison of medical systems as cultural systems. Social Science\& Medicine12, Ik 85-93.

Kleinmann, Arthur 1988. Thel IIness Narratives: Suffering, Heal ing and the Human Condition. New York: Basic Books.

Kuipers, J oel C. 1989. 'Medical discourse' in anthropol ogical context: Views of language and power. M edical Anthropol ogy Quarterly 3, Ik 99-123.

Laderman, Carol 1987. The ambiguity of symbols in the structure of healing. Social Science\& Medicine24: 4, Ik 293-301.

Leiderman, Deborah B. \& Grisso, J ean-Anne 1985. The gomer phenomenon. J ournal of Health and Social Behavior 16, Ik 213-225.

Lorber, J udith 1975. Good patients and bad patients: Conformity and deviance in a general hospital. J ournal of Health and Social Behavior 16, Ik 213-225.

Maseide, Per 1991. Possibly abusive, often benign and always necessary: On power and domination in medical practice. Sociology of Health and IIIness 13: 4, Ik 545-561.

McGuire, Meredith B. 1983. Words of Power: Personal empowerment and healing. Culture, Medicineand Psychiatry 7, Ik 221-240.

Miles, Matthew B. \& Huberman, Michael A. 1994. Qualitative Data Analysis: An Expanded Sourcebook. 2. tr. Newbury Park, CA: Sage. 


\section{Wilbert M. Gesler}

Mishler, Elliot George 1984. The Discourse of M edi cine Dial ectics of M edical Interviews. N orwood: Ablex Publishing Company.

Mugerauer, Robert 1985. Language and the emergence of environment. Seamon, David \& Mugerauer, Robert (toim). Dwelling, Place and Environment. Dordrecht: Martinus Nijhoff, Ik 51-70.

Pile, Steve \& Thrift, Nigel 1995. Mapping the subject. Pile, Steve \& Thrift, Nigel (toim). Mapping theSubject: Geographies of Cultural Transformation. London: Routledge, Ik 13-51.

Pred, Alan 1989. The locally spoken word and local struggles. Environment and Planning D: Society and Space 7, Ik 211-233.

Price, Laurie 1987. Ecuadorian illness stories: Cultural knowledge in natural discource. Holland, Dorothy \& Quinn, Naomi (toim). Cultural models in Language and Thought. Cambridge: Cambridge University Press, Ik 313-342.

Quinn, Naomi \& Holland, Dorothy 1987. Culture and cognition. Holland, Dorothy \& Quinn, Naomi (toim). Cultural models in Languageand Thought. Cambridge: Cambridge University Press, Ik 3-40.

Sontag, Susan 1987. IIIness as Metaphor. New York: Vintage Books.

Spencer, Christopher \& Blades, Mark 1986. Pattern and process: An essay on the relationship between behavioral geography and environmental psychol ogy. Progress in Human Geography 10, Ik 230-248.

Suchman, Anthony L. \& Matthews, Dale A. 1988. What makes the patientdoctor relationship therapeutic? Exploring the connexional dimension of medical care. Annals of I nternal Medicine108, Ik 125-130.

Tambiah, Stanley J . 1968. The magical power of words. Man 3: 2, Ik 175130.

Todd, Alexandra Dundas \& Fisher, Sue 1993. The Social Organization of Doctor-Patient Communication. 2. tr. Norwood: Ablex Publishing Corporation.

Tuan, Yi-Fu 1991. Language and the making of place: A narrativedescriptive approach. Annals of the Association of American Geographers 81: 4, Ik 684-696.

Tuckett, David \& Boulton, M. \& Olson, C. \& Williams, A. 1985. Meetings Between Experts: An Approach to Sharing I deas in Medical Consultations. London: Tavistock.

Turshen, Meredeth 1977. The political ecology of disease. Review of Radical Political Economics 9, Ik 45-60.

Waitzkin, Howard 1981. The social origins of illness: A neglected history. International J ournal of Health Services 11, Ik 77-103. 


\section{Wilbert M. Gesler}

Waitzkin, Howard 1989. A critical theory of medical discourse: I deology, social control and the processing of social context in medical encounters. $\mathrm{J}$ ournal of Health and Social Behavior 30, Ik 220-239. 